\title{
Thyroid hormone disrupting activities of sediment from the Guanting Reservoir, Beijing, China
}

\author{
Jian $\mathrm{Li}^{\mathrm{a}, *}$, Morui $\mathrm{Li}^{\mathrm{a}}$, Shujuan Ren ${ }^{\mathrm{a}}$, Chenglian Feng ${ }^{\mathrm{b}}, \mathrm{Na} \mathrm{Li}^{\mathrm{c}}$ \\ a Engineering Research Center of Groundwater Pollution Control and Remediation, Ministry of Education, College of Water Sciences, Beijing Normal \\ University, Beijing 100875, China \\ b State Key Laboratory of Environmental Criteria and Risk Assessment, Chinese Research Academy of Environmental Sciences, Beijing 100012, China \\ c State Key Laboratory of Environmental Aquatic Chemistry, Research Center for Eco-Environmental Sciences, Chinese Academy of Sciences, P. O. Box 2871, \\ Beijing 100085, China
}

\section{H I G H L I G H T S}

- Yeast bioassays were used to evaluate the TR disrupting activities of the sediments.

- The organic extracts showed TR antagonistic activities.

- The elutriates also significantly antagonized the TR.

- The causes of toxicity in the elutriates appear to be partly related to the heavy metals.

\section{A R T I C L E I N F O}

\section{Article history:}

Received 19 December 2013

Received in revised form 25 March 2014

Accepted 14 April 2014

Available online 21 April 2014

\section{Keywords:}

In vitro bioassay

Thyroid receptor

Thyroid disrupting chemicals

Sediment

\begin{abstract}
A B S T R A C T
In the present study, yeast bioassays were used to evaluate and characterize the thyroid receptor (TR) disrupting activities of the organic extracts and elutriates of the sediments from the Guanting Reservoir, Beijing, China. An accelerated solvent extraction was used to separate the organic extracts, which were subjected to a yeast bioassay. The organic extracts could affect thyroid hormone signaling by decreasing the binding of the thyroid hormone. The TR antagonistic activity equivalents $\left(\mathrm{TEQ}_{\mathrm{bio}}\right)$ referring to amiodarone hydrochloride were calculated and the observed $\mathrm{TEQ}_{\text {bio-organic extracts }}$ ranged from $25.4 \pm 3.7$ to $176.9 \pm 18.0 \mu \mathrm{g} / \mathrm{g}$. Elutriate toxicity tests using the modified yeast bioassay revealed that the elutri-

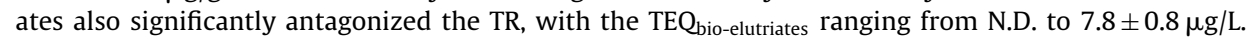
To characterize the toxic compounds, elutriates were extracted by using a C18 cartridge or treated with ethylenediaminetetraacetic acid (EDTA, $30 \mathrm{mg} / \mathrm{L}$ ). The results suggested that the addition of EDTA eliminated over $74.3 \%$ of the total effects, and the chemical analysis revealed that heavy metals, some of which exhibited TR disrupting potency, for example $\mathrm{Zn}$ and $\mathrm{Cd}$, were detectable with higher concentrations in the elutriates. Thus, the cause(s) of toxicity in the elutriate appear to be partly related to the heavy metals.
\end{abstract}

(c) 2014 Elsevier B.V. All rights reserved.

\section{Introduction}

Thyroid hormones (THs) participate in several important physiological processes, including the regulation of energy metabolism, growth and differentiation and the development and maintenance of brain function [1]. Thus, maintaining normal thyroid function is essential for psychological and physiological well-being [2]. However, increasing evidence from animal and in vitro studies indicate that the thyroid is vulnerable to endocrine-disrupting

\footnotetext{
* Corresponding author. Tel.: +86 01058802738; fax: +86 01058802738.

E-mail address: lijian@bnu.edu.cn (J. Li).
}

effects [2]. Industrial chemicals characterized as thyroid-disrupting chemicals (TDCs) include polychlorinated biphenyls (PCBs), dioxins, brominated flame retardants (BFRs), pesticides, perfluorinated chemicals (PFCs), phenols, phthalate esters (PAEs) and perchlorate $[2,3]$.

For many of these dangerous toxic TDCs, aquatic environments serve as the major route of distribution, and the sediments of these environments represent the ultimate sink and long-term source $[4,5]$. A large number of TDCs with strong disrupting potency to the thyroid system are hydrophobic organic compounds, which tend to suspended organic material and to accumulate in the sediment; however, little assessment of thyroid disruptors in sediment samples has been performed. 
Because TDCs are ubiquitously present at trace levels and are widely diverse, biologically based assays may represent a promising method for studying thyroid disrupting effects. Recent studies have suggested that TDCs in the sediment may disturb the amphibian metamorphosis and contribute to the observed global decline of amphibian species [6,7]. Although the in vivo bioassays using the habitats could more precisely describe the toxicity of the sediment, the in vitro bioassays provide a means of a simple, economical and high-throughput biological evaluation of thyroid disrupting effects [8]. Test systems based on the molecular mechanisms of the action of the steroid/thyroid receptor (TR) using the recombined TR gene yeast have been proposed as useful tools to study the thyroid hormone disrupting effects of single compounds, mixtures or environmental extracts $[9,10]$. The yeast assay provides a rapid, easy-to-use in vitro system for detecting the TR ant/agonistic activity of environment samples. Furthermore, the recombined TR gene yeast assay was modified to detect the thyroid-disrupting effects of environmental water samples directly, which does not require the extraction, concentration, or sterilization of the water samples (Supporting Information, Fig. S1) [11].

When examining the sediment toxicity, the sediment extracts and elutriates from the test procedures are normally used [12-14]. The objective of the present study was to evaluate and characterize the thyroid disrupting effect of the sediment collected in the Guanting Reservoir, Beijing. This objective was accomplished through a stepwise approach of first determining the thyroid disrupting effects of the sediment organic extracts using the conventional recombined TR gene yeast assay and then characterizing the thyroid toxicity of the sediment elutriates using the modified yeast assay without sample extraction, concentration, or sterilization.

\section{Materials and methods}

\subsection{Chemicals}

3,3',5-Triiodo-L-thyronine ( $\left.\mathrm{T}_{3}, 95 \%\right)$, ethylenediaminetetraacetic acid (EDTA, 99\%) and dimethylsulfoxide ([DMSO], 99.5\%) were purchased from Sigma Chemical (St. Louis, MO, USA). Amiodarone hydrochloride $(\mathrm{AH})$ was purchased from Shanghai Pharmaceutical (Shanghai, China). HPLC grade dichloromethane (DCM), acetone and hexane were purchased from Fisher Scientific (Fair Lawn, NJ).

\subsection{Sample collection and processing}

The Guanting Reservoir, located northwest of Beijing, China, is one of the two main water resources used by the agricultural, industrial and civilian populations of Beijing. The surface sediment samples (up to the top $20 \mathrm{~cm}$ ) were collected in May 2012 from the Guanting Reservoir [15]. The locations of the eight sampling sites are displayed in Fig. 1. Each of the sediment samples $(500 \mathrm{~g})$ were collected into glass jars, which were pre-washed with DCM and acetone, and stored at $-20^{\circ} \mathrm{C}$ after being transported to the laboratory until further analyses.

\subsection{Sediment organic extracts preparation}

After being freeze-dried and meshed, $5 \mathrm{~g}$ of each sediment sample were extracted with DCM/acetone $(1: 1, \mathrm{v} / \mathrm{v})$ using accelerated solvent extraction (ASE 200, Dionex Corporation, Sunnyvale, CA). Sample extraction was performed using the procedure reported by $\mathrm{Bu}$ et al. [16]. The extraction temperature was $130^{\circ} \mathrm{C}$, and extraction pressure was 1500 psi. Both the preheating time and the static time were set to $5 \mathrm{~min}$. A total flush volume of $100 \%$ of the cell volume and a purge time of $200 \mathrm{~s}$ with nitrogen was used. The final extraction volume was approximately $20 \mathrm{~mL}$ with two extraction cycles. The extracts were completely condensed to approximately

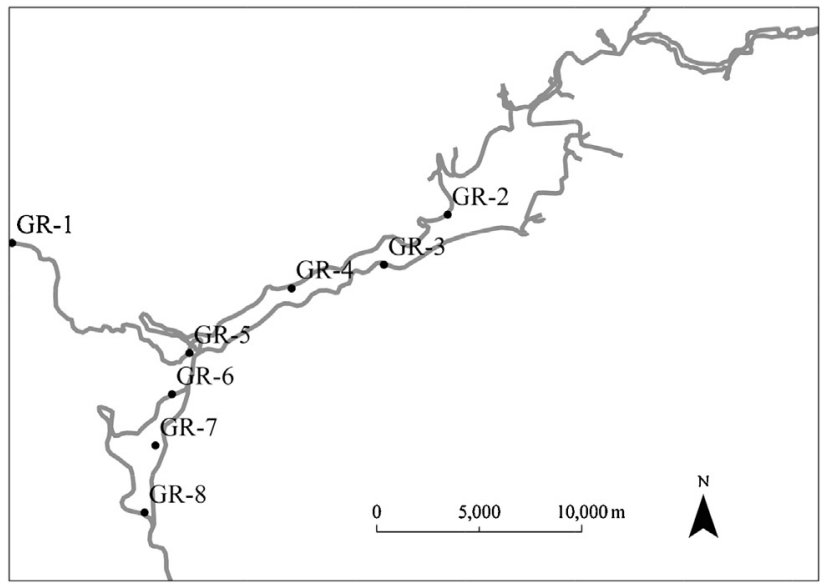

Fig. 1. Sampling sites in the Guanting Reservoir.

$2 \mathrm{~mL}$ by a rotary evaporator (Büchi R-200, Switzerland). The concentrated extracts were evaporated to near dryness in a gentle flow of nitrogen gas, then redissolved in $0.5 \mathrm{~mL}$ DMSO and stored at $-20^{\circ} \mathrm{C}$ before performing the bioassay [17]. Six concentration levels of test solutions were obtained by 2 -fold dilution of each sediment raw extract, and DMSO was used as a solvent control for the conventional yeast assay.

\subsection{Sediment elutriate preparation}

The elutriates were prepared $24 \mathrm{~h}$ before the start of the bioassay according to the procedure reported by Bosch et al. [18]. One hundred grams of fresh sediment was gently mixed to $1 \mathrm{~L}$ of artificial water (ASTM hard) [19] in a 1:10 wet-sediment to liquid volumetric ratio during $24 \mathrm{~h}$ at $10 \mathrm{rpm}$ in a rotatory wheel at $20^{\circ} \mathrm{C}$. Then, the sediment-water slurry was left to settle for $24 \mathrm{~h}$, and the overlaying water was filtered through a glass microfiber $(0.7 \mu \mathrm{m}$; Waterman, England) to obtain the filtered elutriate fraction. After filtration, $500 \mathrm{~mL}$ samples of the filtered elutriates were collected, which were stored at $4{ }^{\circ} \mathrm{C}$ in glass containers until the modified yeast assays were performed.

EDTA $(30 \mathrm{mg} / \mathrm{L})$ was added to the $200 \mathrm{~mL}$ elutriates. Other $200 \mathrm{~mL}$ elutriates were extracted by using a C18 cartridge $(500 \mathrm{mg}$, Waters, USA). The cartridges were forced under vacuum at a flow rate of approximately $6 \mathrm{~mL} / \mathrm{min}$. After extraction, $200 \mathrm{~mL}$ elutriate residual was also collected for bioassay by the modified method [20]. Silica sand was used as procedure blanks.

Sediment samples were digested following a reported method using $69 \%$ high-purity $\mathrm{HNO}_{3}$ and $37 \% \mathrm{HCl}$ [21]. The concentrations of $\mathrm{Cd}, \mathrm{Cr}, \mathrm{Ni}, \mathrm{Cu}, \mathrm{Zn}$ and $\mathrm{Pb}$ in the sediment samples and the elutriate samples were analyzed by using ICP-MS (Thermo Scientific, Waltham, MA) as described by Wang et al. [21]. For quality assurance and control, the recovery rates of heavy metals were detected and were over $81.4 \%$.

\subsection{The conventional yeast assay}

The bioassays, including the agonistic and the antagonistic activity tests, were conducted using the procedure described by Li et al. [9]. All experiments were performed in triplicate. Each assay group was comprised of the sample, the positive control $\left(\mathrm{T}_{3}\right.$ for agonistic activity or $\mathrm{T}_{3}+\mathrm{AH}$ for antagonistic activity), the negative control (DMSO) and the procedural blank.

The yeast strain hTR-GRIP1 was grown overnight at $30^{\circ} \mathrm{C}$ and $130 \mathrm{rpm}$ with vigorous shaking. During the assay, the exponentially growing overnight cultures were diluted with a synthetic dextrose/-Leu/-Trp (SD/-Leu/-Trp) medium to an $\mathrm{OD}_{600 \mathrm{~nm}}$ of 0.75 . 
The serial dilutions $(5 \mu \mathrm{L})$ of organic extracts were combined with $995 \mu \mathrm{L}$ of medium containing $5 \times 10^{3}$ yeast cells $/ \mathrm{mL}$, resulting in a test culture. To assess the antagonistic activities, the extracts were tested in the presence of $2.5 \times 10^{-7} \mathrm{~mol} / \mathrm{L} \mathrm{T}_{3}$, which produced a submaximal stimulatory response. The DMSO volume did not exceed $1.0 \%$ of the total volume. Two hundred microliters of the test cultures were transferred into each well of the 96-well plate and incubated at $30^{\circ} \mathrm{C}$ with vigorous orbital shaking ( $800 \mathrm{rpm}$ ) on a titer plate shaker (Heidolph TITRAMAX 1000, Germany) for $2 \mathrm{~h}$, then the cell density of the culture was measured at a wavelength of $600 \mathrm{~nm}$ (TECAN GENios A-5002, Austria). A $50 \mu \mathrm{L}$ test culture was transferred to a new 96-well plate, and, after the addition of $120 \mu \mathrm{L}$ of Z-buffer and $20 \mu \mathrm{L}$ of chloroform, the assays were carefully mixed (vortex $25 \mathrm{~s}$ ) and preincubated for $5 \mathrm{~min}$ at $30^{\circ} \mathrm{C}$. The enzyme reaction was initiated by adding $40 \mu \mathrm{L}$ of $o$-nitrophenyl- $\beta$ $\mathrm{D}$-galactopyranoside (13.3 mM, dissolved in Z-buffer). The assays were incubated at $30^{\circ} \mathrm{C}$ for $60 \mathrm{~min}$ on a titer plate shaker. The reactions were terminated by adding $100 \mu \mathrm{L}$ of $1 \mathrm{~mol} / \mathrm{L} \mathrm{Na}_{2} \mathrm{CO}_{3}$. $200 \mu \mathrm{L}$ of the supernatant was transferred into a new 96 -well plate, and the $\mathrm{OD}_{420 \mathrm{~nm}}$ was determined. The $\beta$-galactosidase activity was calculated according to equations described by Gaido et al. [22].

\subsection{The modified yeast assay}

The exponentially growing overnight cultures were diluted using a $\mathrm{SD} /$-Leu/-Trp medium to an $\mathrm{OD}_{600 \mathrm{~nm}}$ of 0.75 . Five-milliliter cultures were centrifuged at $1000 \times g$ for 5 min (Sigma Laborzentrifugen $2 \mathrm{~K} 15$, Germany), and the supernatant was discarded. Then, the yeast cells and $0.5 \mathrm{~mL}$ of $10 \times \mathrm{SD} /$-Leu/-Trp medium were added to $4.5 \mathrm{~mL}$ of the test solutions, yielding a test culture. In the antagonistic test, $12.5 \mu \mathrm{L}$ of $10^{-4} \mathrm{~mol} / \mathrm{LT}_{3}$ (dissolved in DMSO) were added to the test culture, in which the volume of DMSO did not exceed $0.25 \%$ of the total volume. The test cultures were incubated at $30^{\circ} \mathrm{C}$ with vigorous orbital shaking $(130 \mathrm{rpm})$ on a shaking incubator (HZQ-Q China) for $2 \mathrm{~h}$. Two hundred microliters of the test cultures were transferred into each well of the 96-well plate, and the cell density of the culture was measured at a wavelength of $600 \mathrm{~nm}$ (TECAN GENios A-5002, Austria). The $\beta$-galactosidase assay kit (Tropix, Bedford, MA, USA), which combines direct cell lysis with rapid ultra-sensitive chemiluminescent detection of $\beta$ galactosidase reporter enzyme and is suited for the transformed yeast cells, was purchased for use in the analysis. A $100 \mu \mathrm{L}$ test culture was transferred to a new 96 -well plate. After addition of $100 \mu \mathrm{L}$ of the reaction buffer, the assays were incubated at $30^{\circ} \mathrm{C}$ with vigorous orbital shaking $(800 \mathrm{rpm})$ on a titer plate shaker (Heidolph TITRAMAX 1000, Hamburg, Germany) for $60 \mathrm{~min}$. Two hundred microliters of the supernatant was transferred into a new 96-well plate, and the light emission was measured (TECAN GENios A-5002, Austria). The $\beta$-galactosidase activity was calculated according to equations described by Balsiger et al. [23].

\subsection{Cytotoxicity}

To ensure that the increased/reduced activities observed by the bioassay were caused by true agonistic/antagonistic responses and not by cytotoxicity, the viability was measured in cells exposed to organic extracts or to elutriate at the maximum assay concentration. The details are described in the Supporting Information.

\subsection{Data analysis}

To identify the specific compounds responsible for the TRdisrupting activities, the putative thyroid-disrupting chemicals in the sediment were quantified using the toxic equivalent (TEQ) approach. Briefly, $\beta$-galactosidase expression was inhibited by the sediment elutriate samples in the presence of submaximal $T_{3}$
Table 1

The toxic equivalent (TEQ) of the organic extracts of the sediments and the elutriates obtained from the yeast bioassays. AH: amiodarone hydrochloride, N.D.: not detected.

\begin{tabular}{lll}
\hline $\begin{array}{l}\text { Concentrations at } \\
\text { sampling sites }\end{array}$ & $\begin{array}{l}\mathrm{TEQ}_{\text {bio-organic extracts }}(\mathrm{AH} \\
\mu \mathrm{g} / \mathrm{g})\end{array}$ & $\begin{array}{l}\mathrm{TEQ}_{\text {bio-elutriates }}(\mathrm{AH} \\
\mu \mathrm{g} / \mathrm{L})\end{array}$ \\
\hline GR1 & $123.7 \pm 20.9$ & $7.8 \pm 0.8$ \\
GR2 & $30.1 \pm 3.8$ & $0.5 \pm 0.0$ \\
GR3 & $128.7 \pm 12.0$ & N.D. \\
GR4 & $77.5 \pm 18.1$ & N.D. \\
GR5 & $25.4 \pm 3.7$ & $0.9 \pm 0.1$ \\
GR6 & $176.9 \pm 18.0$ & N.D. \\
GR7 & $95.6 \pm 11.6$ & N.D. \\
GR8 & $33.5 \pm 4.0$ & N.D. \\
Blank & N.D. & N.D. \\
\hline
\end{tabular}

concentrations, and the bioassay-derived AH equivalent concentrations ( $\left.\mathrm{TEQ}_{\text {bio-elutriates }}\right)$ were derived by the known TR antagonist $\mathrm{AH}$ concentration necessary to produce an equivalent reduction in TR antagonistic activity [11]. The concentration-dependent response curves of the organic extracts were expressed and then converted to $\mathrm{AH}$ equivalent concentrations ( $\mathrm{TEQ}_{\mathrm{bio} \text {-organic extracts }}$ ). The details are described in the Supporting Information.

\section{Results}

\subsection{Cell viability and system credibility}

To examine the $\beta$-galactosidase inhibition that was induced by the interaction of TDCs with the TR, we tested the bioassay system credibility, as described in the Supporting Information. These results suggest that the sediment samples (including sediment organic extracts and sediment elutriates) do not suppress TR gene expression and that the inhibition activities of the sediment samples were specific to the TR (Supporting Information, Figs. S2 and S3).

To account for stimulatory or toxic matrix effects on the yeast, we tested the cytotoxicity values. The results revealed a lack of a significant change in yeast cell viability (Supporting Information, Fig. S4).

\subsection{TR ant/agonistic activity of the organic extracts of the sediment}

The thyroid-disrupting effects of the organic extracts of the sediment were detected by the conventional yeast assay, revealing that the agonistic TR activities were not detected in all sediment samples (Fig. 2a). However, all the organic extracts of the sediment exhibited antagonistic TR activities that inhibited $\beta$ galactosidase expression. The blank samples did not disrupt the TR, as displayed in Fig. 2. The concentration-dependent curves of the antagonistic TR activities are displayed in Fig. 2b. The corresponding $\mathrm{TEQ}_{\text {bio-organic extracts }}$ ranged from $25.4 \pm 3.7$ to $176.9 \pm 18.0 \mu \mathrm{g} / \mathrm{g}$ $\mathrm{AH}$ (Table 1) and the average $\mathrm{TEQ}_{\text {bio-organic extracts }}$ for the Guanting reservoir was $86.4 \mu \mathrm{g} / \mathrm{g} \mathrm{AH}$. The highest activities were found in GR1, GR3 and GR6. As shown in Fig. 1, GR1 represents the condition of the Yongding River; GR3 and GR6 are the estuaries downstream of the Yongding River and the Guishui River, respectively.

\subsection{TR ant/agonistic activity of the elutriates of the sediment}

Agonistic TR activities were not observed in the elutriates of the sediment (Fig. 3a). However, the sediment elutriates exerted antagonistic TR activities. The inhibition activities of the elutriates of the sediment ranged from $0.3 \%$ to $24.4 \%$. The data for the 


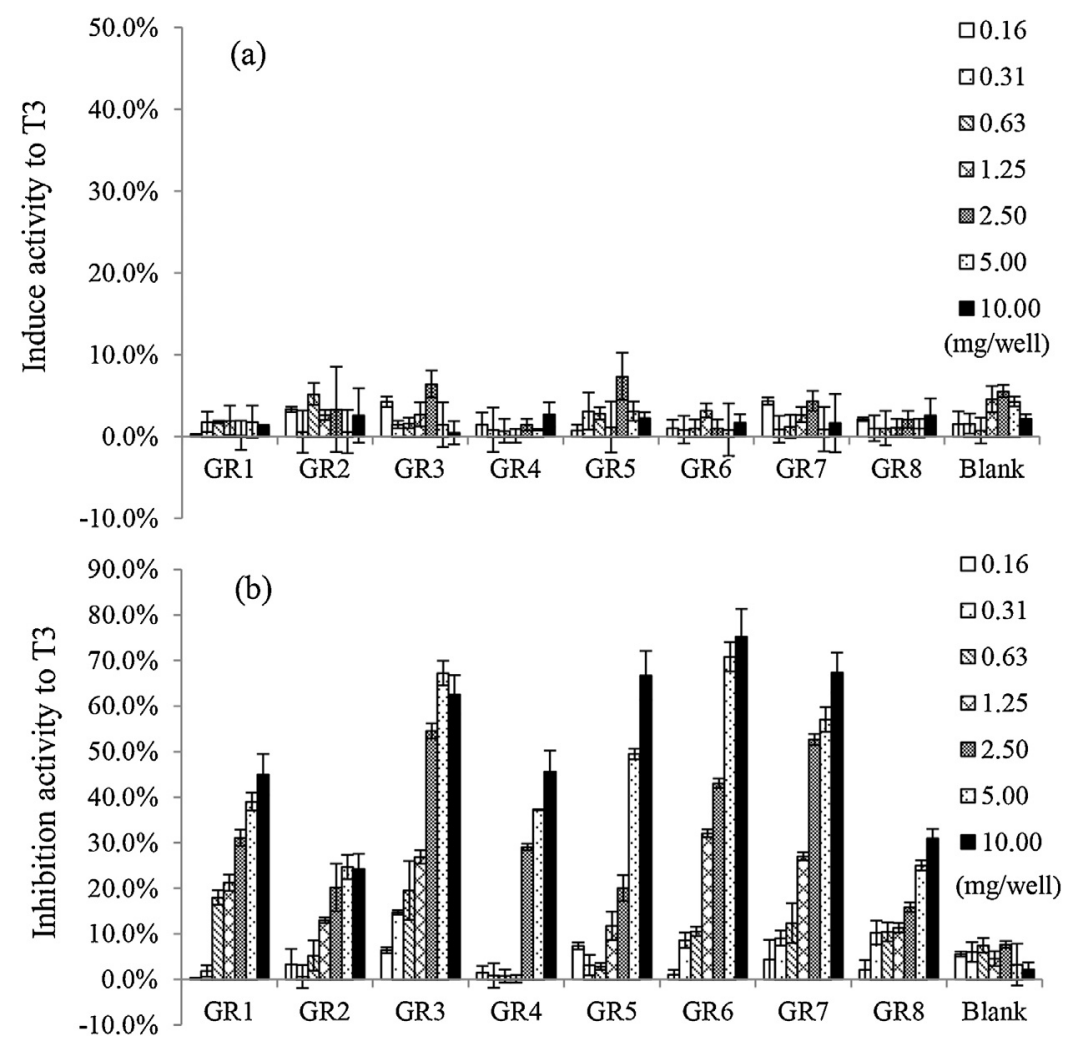

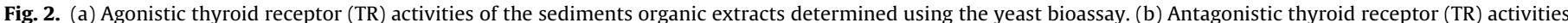

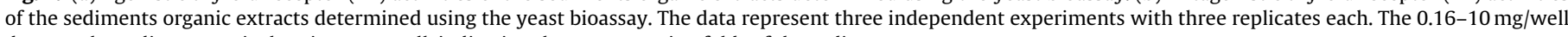
denotes the sediment equivalent in every well, indicating the concentration folds of the sediment.

sediment elutriates were used to quantify the antagonistic TR activities. The TEQ $\mathrm{bio}_{\text {-elutriates }}$ ranged from N.D. to $7.8 \pm 0.8 \mu \mathrm{g} / \mathrm{L} \mathrm{AH}$, and the highest activities were observed in GR1, GR2 and GR5.

\subsection{Characterization of the TR antagonists in the elutriates of the sediment}

To characterize the responsible thyroid-active compounds, the elutriates of the sediment were extracted by using a C18 cartridge. After extraction, the thyroid inhibition activities of the residual elutriate decreased (Fig. 3b). For some sediment elutriates (GR1, GR2 and GR5), which had significant inhibition activities compared with that of the control, the extraction could eliminate less than $30.8 \%$ of the total effect produced by TR antagonists. Furthermore, EDTA $(30 \mathrm{mg} / \mathrm{L}$ ) was added to the sediment elutriates that did not have cytotoxicity and effect the $\beta$-galactosidase activity in the blank sample. After addition of EDTA to the sediment elutriates, the inhibition activities decreased significantly (Fig. 3b). For some sediment elutriates (GR1, GR2 and GR5), EDTA could significantly eliminate over $74.3 \%$ of the total effect produced by the TR antagonists, suggesting that metals might contribute to the TR antagonistic activity. As a result, the concentrations of heavy metals in the sediment samples and elutriate samples were measured (Table 2). The total metal concentrations in the elutriate samples ranged from $73.44 \pm 4.04$ to $302.64 \pm 16.02 \mu \mathrm{g} / \mathrm{L}$. Zn was dominant in the sediment elutriates, with an average concentration of $117.62 \mu \mathrm{g} / \mathrm{L}$. Moreover, the heavy metals were also detectable in the sediment samples from all the locations, at concentrations ranging from $117.73 \pm 5.53$ to $455.21 \pm 15.59 \mu \mathrm{g} / \mathrm{g}$. Zn $(37.45 \pm 1.65-251.18 \pm 11.90 \mu \mathrm{g} / \mathrm{g})$ also exhibited higher concentrations than the other heavy metals in the sediment samples.

\section{Discussion}

In the present study, the agonistic TR activities were not detected in all of the sediment organic extracts. However, all the samples exhibited antagonistic TR activities, and the AH equivalent concentration in the sediment organic extracts ranged from $25.4 \pm 3.7$ to $176.9 \pm 18.0 \mu \mathrm{g} / \mathrm{g}$. The exclusively antagonized TR activity of the water samples collected from the same location in the Guanting Reservoir has been previously reported [11]. Gutleb et al. [24] also reported, using the T-screen method, that apolar sediment extracts exhibited TR antagonist activities. All of this evidence suggests that the extractable compounds exhibited high capacity to disturb the thyroid function via TR.

As displayed in Fig. 1, two large rivers, Yongding River and Guishui River, which receive a large amount of agricultural runoff, sewage discharge and wastewater effluent, are emptied into the Guanting Reservoir. The water quality of the Guanting Reservoir was proven to be influenced by these rivers. The sediment organic extracts in GR1, GR3 and GR6 exerted a higher TR antagonism than that of the other samples, possibly because of the input from the rivers and the transportation of TDCs in the sediment. The TR disrupting effect of GR1 was reflected in the condition of the Yongding River, which has been reported to harbor over $80 \%$ of the pollutants eventually observed in the Guanting Reservoir [25]. Some TDCs, including PAEs, endocrine-disrupting pesticides and PCBs, have been detected in the Yongding River at high concentrations [26]. The GR3 and GR6 sites are located downstream of the estuaries of the Guishui River and Yongding River, respectively. Similar to the Yongding River, more chemicals with TR-disrupting activity were also identified in the Guishui River [27]. Interestingly, in the water samples, a higher TR antagonism was found at the estuary sites; however, in the sediment samples, the higher effect was found downstream of the estuary sites, which may be attributed to 


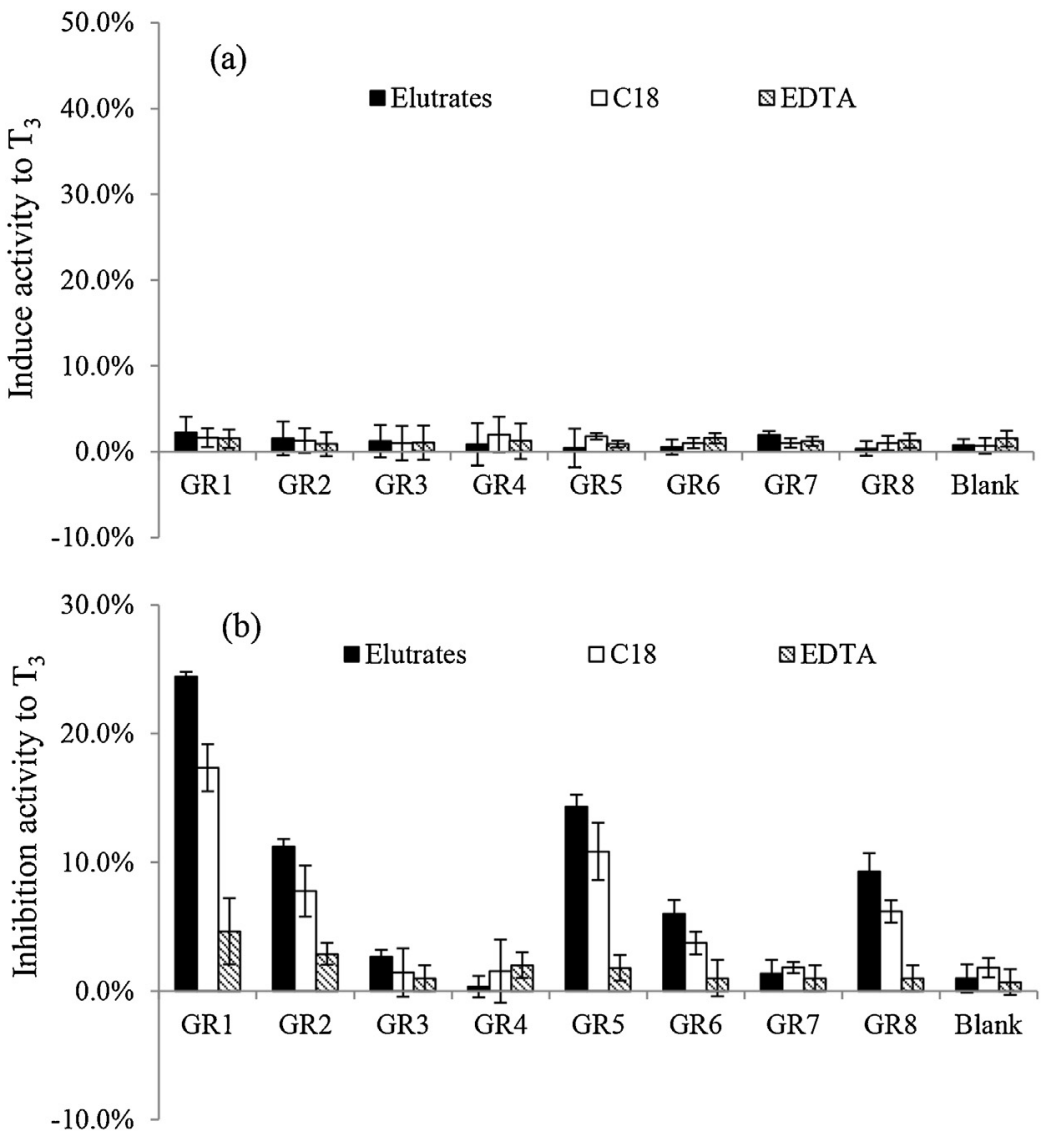

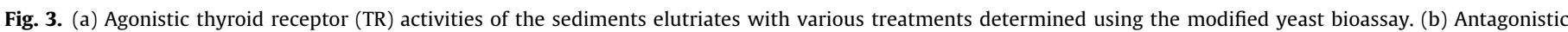

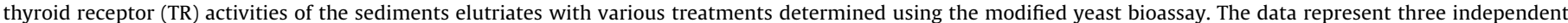
experiments with three replicates each. C18: solid phase extraction using a C18 cartridge. EDTA: addition of $30 \mathrm{mg} / \mathrm{L}$ of ethylenediaminetetraacetic acid (EDTA).

the transport of the TDCs. Sonneveldt and Laane [28] reported that several of the sediment-associated, persistent and toxic chemicals known to induce thyroid disrupting effects are bound to the small sediment particles and can be transported to locations far from the original inputting site. These findings suggest that the Guanting Reservoir sediment likely exerts effect on TH signaling and that the geographical location impacts this effect due to the input and transport of the TDCs. Although the major TDCs in the sediment organic extracts are not identified yet, these results are very promising for further research on the thyroid disruption of these chemicals to the benthic species.

An elutriate sediment toxicity test, designed to detect the release of chemical contaminants from the sediment suspended in the water column, provides a better measure of the amount of a substance that is exchanged between the sediment and the aqueous phase [29,30]. Cheung et al. [31] suggested that the elutriate sediment toxicity test provides a better measure of the bioavailable substances in the sediment. Previous research has focused on

Table 2

Concentrations of the heavy metals in the sediments and the sediment elutriates from the Guanting Reservoir, Beijing, China.

\begin{tabular}{|c|c|c|c|c|c|c|c|}
\hline & $\mathrm{Cd}$ & $\mathrm{Zn}$ & $\mathrm{Cr}$ & $\mathrm{Ni}$ & $\mathrm{Cu}$ & $\mathrm{Pb}$ & $\sum$ Metals \\
\hline \multicolumn{8}{|c|}{ Sediment $(\mu g / g)$} \\
\hline GR1 & $1.07 \pm 0.10$ & $251.18 \pm 11.90$ & $51.52 \pm 4.21$ & $18.10 \pm 1.22$ & $45.68 \pm 3.34$ & $87.66 \pm 3.24$ & $455.21 \pm 15.59$ \\
\hline GR2 & $0.19 \pm 0.02$ & $50.58 \pm 3.21$ & $35.98 \pm 3.38$ & $20.97 \pm 2.01$ & $18.00 \pm 1.29$ & $15.63 \pm 0.77$ & $141.35 \pm 4.26$ \\
\hline GR3 & $0.12 \pm 0.02$ & $45.41 \pm 1.29$ & $34.59 \pm 2.76$ & $19.69 \pm 2.13$ & $16.90 \pm 1.24$ & $15.11 \pm 1.32$ & $131.83 \pm 3.24$ \\
\hline GR4 & $0.16 \pm 0.01$ & $37.45 \pm 1.65$ & $37.17 \pm 3.24$ & $15.19 \pm 1.21$ & $13.02 \pm 1.31$ & $14.74 \pm 1.89$ & $117.73 \pm 5.53$ \\
\hline GR5 & $0.20 \pm 0.01$ & $64.40 \pm 5.78$ & $45.79 \pm 1.79$ & $19.83 \pm 0.97$ & $19.44 \pm 0.85$ & $21.76 \pm 2.08$ & $171.41 \pm 9.78$ \\
\hline GR6 & $0.46 \pm 0.02$ & $103.39 \pm 3.54$ & $57.45 \pm 4.62$ & $34.59 \pm 2.22$ & $40.49 \pm 2.28$ & $31.61 \pm 1.69$ & $268.00 \pm 14.33$ \\
\hline GR7 & $0.28 \pm 0.03$ & $62.25 \pm 4.68$ & $48.20 \pm 3.66$ & $27.76 \pm 0.96$ & $27.40 \pm 1.67$ & $18.93 \pm 0.65$ & $184.81 \pm 5.09$ \\
\hline GR8 & $0.12 \pm 0.01$ & $46.75 \pm 2.33$ & $47.93 \pm 1.74$ & $19.98 \pm 0.63$ & $18.10 \pm 0.87$ & $13.61 \pm 1.34$ & $146.50 \pm 6.92$ \\
\hline \multicolumn{8}{|c|}{ Sediment elutriates $(\mu g / L)$} \\
\hline GR1 & $0.21 \pm 0.01$ & $259.81 \pm 12.33$ & $12.37 \pm 1.99$ & $7.68 \pm 0.36$ & $20.13 \pm 1.65$ & $2.45 \pm 0.30$ & $302.64 \pm 16.02$ \\
\hline GR2 & $0.09 \pm 0.00$ & $126.26 \pm 11.56$ & $5.99 \pm 3.68$ & $3.70 \pm 0.24$ & $12.52 \pm 1.39$ & $1.37 \pm 0.16$ & $149.92 \pm 13.45$ \\
\hline GR3 & $0.09 \pm 0.01$ & $125.83 \pm 9.65$ & $5.67 \pm 1.26$ & $3.50 \pm 0.19$ & $9.53 \pm 0.63$ & $1.04 \pm 0.08$ & $145.64 \pm 10.40$ \\
\hline GR4 & $0.08 \pm 0.01$ & $84.79 \pm 8.47$ & $6.84 \pm 0.37$ & $3.90 \pm 0.28$ & $11.78 \pm 0.93$ & $1.84 \pm 0.12$ & $109.23 \pm 8.08$ \\
\hline GR5 & $0.13 \pm 0.00$ & $177.05 \pm 13.25$ & $31.37 \pm 4.00$ & $4.39 \pm 0.32$ & $14.84 \pm 0.21$ & $1.25 \pm 0.07$ & $229.03 \pm 17.29$ \\
\hline GR6 & $0.13 \pm 0.01$ & $38.37 \pm 2.65$ & $20.70 \pm 0.92$ & $5.51 \pm 0.28$ & $29.82 \pm 1.69$ & $1.07 \pm 0.06$ & $95.59 \pm 5.05$ \\
\hline GR7 & $0.09 \pm 0.00$ & $84.14 \pm 3.19$ & $9.72 \pm 0.62$ & $3.86 \pm 0.11$ & $16.27 \pm 1.32$ & $2.41 \pm 0.13$ & $116.48 \pm 5.15$ \\
\hline GR8 & $0.07 \pm 0.00$ & $44.75 \pm 2.58$ & $6.25 \pm 0.57$ & $3.85 \pm 0.38$ & $15.00 \pm 1.01$ & $3.51 \pm 0.26$ & $73.44 \pm 4.04$ \\
\hline
\end{tabular}


the thyroid-disrupting effects of organic extracts from sediments. To the best of our knowledge, this is the first report in which sediment elutriates are reported to influence thyroid hormone receptor dependent processes in yeast cells. The results of the bioassay indicated that sediment elutriates collected from Guanting Reservoir had TR antagonistic activities but not agonistic activities. The $\mathrm{TEQ}_{\text {bio-elutriates }}$ ranged from N.D. to $7.8 \pm 0.8 \mu \mathrm{g} / \mathrm{L} \mathrm{AH}$, which were within the range of the values reported for environment waters [32-34]. Similar to the water samples reported previously [11], the higher TR antagonism levels in the sediment elutriates were found at GR1, GR2 and GR5, which are possibly related to the inputs from the Yongding River and the Guishui River.

The TR antagonistic potency in the sediment elutriates of the Guanting Reservoir was possibly due to some release of TDCs from the sediment into the water, such as heavy metals and some hydrophilic organic compounds. Despite the TR-disrupting effects that have been confirmed in the sediment elutriates, characterizing the toxic compounds remains problematic due to the chemical complexity of the environmental samples. In this study, we compared the baseline toxicity of the entire elutriate to that after extraction using a C18 cartridge and by treatment with EDTA, and observed that the reduced toxicity of the elutriates after the addition of EDTA was higher than that after extraction by the C18 cartridge, indicating that the cause(s) of toxicity in the sediment elutriates appear to be partly related to the heavy metals. Furthermore, the concentrations of the heavy metals in the sediment elutriates were determined, and $\mathrm{Zn}$ was found to be dominant in the sediment elutriates, with an average concentration of $117.62 \mu \mathrm{g} / \mathrm{L}$. The available data on thyroid disrupting effects of heavy metals mediated by the interaction with TR are limited. A previous study reported that zinc is an integral part of TR proteins and is crucial for binding the receptors to their target genes [35]. Surks et al. [36] reported that the addition of $\mathrm{ZnCl}_{2}, \mathrm{CuCl}_{2}, \mathrm{CdCl}_{2}$ and $\mathrm{NiCl}_{2}$ resulted in a concentration-dependent inhibition of the binding of $\mathrm{T}_{3}$ to TR, and the concentration of $8 \times 10^{-7} \mathrm{~mol} / \mathrm{L} \mathrm{ZnCl}_{2}$ resulted in a significant decrease in specific binding of $\left[{ }^{125} \mathrm{I}\right] \mathrm{T}_{3}$ by nuclear receptors. Furthermore, the inhibitions of $\mathrm{ZnCl}_{2}$ and $\mathrm{CdCl}_{2}$ were eliminated after the addition of EDTA. Sciaudone et al. [37] also supported that zinc chelation enhances the ability of thyroid hormone to induce target gene expression in rat pituitary tumor cells (GH3). Taken together, these results support the proposition that heavy metals, especially Zn, may contribute to the thyroid toxicity of the sediment elutriates in the Guanting Reservoir.

Sediments can absorb and accumulate heavy metals and act as a contamination source, even long after the pollution has been abated [38]. In the present study, a high level of heavy metals was found in the sediments of the Guanting Reservoir, and $\mathrm{Zn}$, which exhibited stronger TR disrupting potency, was noticeably higher in the sediments compared to those without TR disrupting potency. These compounds contained in the sediments might impose adverse effects on aquatic organisms and humans through the food web. Furthermore, the managing of the reservoir and the river input may expose the sediments to scouring action, potentially mobilizing metals in the water column and creating conditions toxic to aquatic organisms. Of course, the total heavy metal concentrations only provide incomplete information on the assessment of their toxicological effects. In the next step, the chemical forms of the heavy metals in the sediments and the elutriates would be analyzed.

\section{Conclusion}

In summary, yeast bioassays were utilized to evaluate and characterize the TR agonistic and antagonistic activities of the sediment samples collected from the Guanting Reservoir. Our results suggest that sediment organic extracts and elutriates may affect $\mathrm{TH}$ signaling by decreasing the binding of the standard TR ligand $\left(T_{3}\right)$. Moreover, heavy metals may play an important role in the antagonistic TR activities in the sediment elutriates from the Guanting Reservoir water. Therefore, selective organic extraction procedures, which have been largely used to assess the endocrine disrupting activities of the sediment, do not necessarily reflect the thyroid toxicological effects because heavy metals usually are removed in the pretreatment process. An elutriate sediment toxicity test may be an important supplement for the organic extraction toxicity test by providing more information and more precisely describing the complications of the natural environment.

\section{Acknowledgements}

This study was supported by the National Natural Science Foundation of China (41001351), the Fundamental Research Funds for the Central Universities (2012LYB35), National High-tech R\&D Program of China (863 Program, 2012AA06A302) and Governmental Public Industry Research Special Funds for projects (201201032).

\section{Appendix A. Supplementary data}

Supplementary data associated with this article can be found, in the online version, at http://dx.doi.org/10.1016/ j.jhazmat.2014.04.021.

\section{References}

[1] A.J. Murk, E. Rijntjes, B.J. Blaauboer, R. Clewell, K.M. Crofton, M.M.L. Dingemans, J.D. Furlow, R. Kavlock, J. Kohrle, R. Opitz, T. Traas, T.J. Visser, M.H. Xia, A.C. Gutleb, Mechanism-based testing strategy using in vitro approaches for identification of thyroid hormone disrupting chemicals, Toxicol. In Vitro 27 (2013) 1320-1346

[2] M. Boas, U. Feldt-Rasmussen, K.M. Main, Thyroid effects of endocrine disrupting chemicals, Mol. Cell. Endocrinol. 355 (2012) 240-248.

[3] M.H. Long, M. Ghisari, E.C. Bonefeld-Jorgensen, Effects of perfluoroalkyl acids on the function of the thyroid hormone and the aryl hydrocarbon receptor, Environ. Sci. Pollut. Res. 20 (2013) 8045-8056.

[4] G.A. Burton, Sediment quality criteria in use around the world, Limnology 3 (2002) 65-75

[5] H.S. Chang, K.H. Choo, B. Lee, S.J. Choi, The methods of identification, analysis, and removal of endocrine disrupting compounds (EDCs) in water, J. Hazard Mater. 172 (2009) 1-12.

[6] A.C. Gutleb, M. Schriks, L. Mossink, J.H.J. van den Berg, A.J. Murk, A synchronized amphibian metamorphosis assay as an improved tool to detect thyroid hormone disturbance by endocrine disruptors and apolar sediment extracts, Chemosphere 70 (2007) 93-100.

[7] J.H.K. Pechmann, H.M. Wilbur, Putting declining amphibian populations in perspective: natural fluctuations and human impacts, Herpetologica 50 (1994) 65-84.

[8] R.L. Johnson, J.Y. Hwang, L.A. Arnold, R.L. Huang, J. Wichterman, I. Augustinaite C.P. Austin, J. Inglese, R.K. Guy, W.W. Huang, A quantitative high-throughput screen identifies novel inhibitors of the interaction of thyroid receptor beta with a peptide of steroid receptor coactivator 2, J. Biomol. Screen 16 (2011) 618-627.

[9] J. Li, M. Ma, Z. Wang, A two-hybrid yeast assay to quantify the effects of xenobiotics on thyroid hormone-mediated gene expression, Environ. Toxicol. Chem. 27 (2008) 159-167.

[10] J. Li, M. Chen, Z.J. Wang, M. Ma, X.Z. Peng, Analysis of environmental endocrine disrupting activities in wastewater treatment plant effluents using recombinant yeast assays incorporated with exogenous metabolic activation system, Bio. Environ. Sci. 24 (2011) 132-139.

[11] J. Li, S.J. Ren, S. Han, N. Li, A yeast bioassay for direct measurement of thyroid hormone disrupting effects in water without sample extraction, concentration, or sterilization, Chemosphere 100 (2014) 139-145.

[12] W. Brack, R. Altenburger, U. Ensenbach, M. Moder, H. Segner, G. Schuurmann, Bioassay-directed identification of organic toxicants in river sediment in the industrial region of Bitterfeld (Germany) - a contribution to hazard assessment, Arch. Environ. Contam. Toxicol. 37 (1999) 164-174.

[13] R.M. Burgess, M.G. Cantwell, M.C. Pelletier, K.T. Ho, J.R. Serbst, H.F. Cook, A. Kuhn, Development of a toxicity identification evaluation procedure for characterizing metal toxicity in marine sediments, Environ. Toxicol. Chem. 19 (2000) 982-991.

[14] B.M. Phillips, B.S. Anderson, J.W. Hunt, B. Thompson, S. Lowe, R. Hoenicke, R. Tjeerdema, Causes of sediment toxicity to Mytilus galloprovincialis in San Francisco Bay California, Arch. Environ. Contam. Toxicol. 45 (2003) 492-497. 
[15] MEP (Ministry of Environmental protection of the People's Republic of China), Technical Specifications Requirements for Monitoring of Surface Water and Waste Water, HJ/T 91-2002, MEP, Beijing, 2002.

[16] O.W. Bu, D.H. Wang, Z.J. Wang, Development of a high throughout method for the screening of polychlorinated biphenyls in sediments/soils using deconvolution technologies, in: The International Conference on Risk Assessment and the Fifth Session of the 13th Annual Conference, Tianjin, China, 2012.

[17] M. Qiao, C.X. Wang, S.B. Huang, D.H. Wang, Z.J. Wang, Composition, sources and potential toxicological significance of PAHs in the surface sediments of the Meiliang Bay, Taihu Lake, China, Environ. Int. 32 (2006) 28-33.

[18] C. Boscha, A. Olivares, M. Faria, J.M. Navas, I. del Olmo, J.O. Grimalt, B. Pina, C. Barata, Identification of water soluble and particle bound compounds causing sublethal toxic effects. A field study on sediments affected by a chlor-alkali industry, Aquat. Toxicol. 94 (2009) 16-27.

[19] ASTM, Standard methods for measuring the toxicity of sediment-associated contaminants with freshwater invertebrates, in: Annual Book of ASTM Standards, ASTM, Philadelphia, 1999

[20] Y.X. Fang, G.G. Ying, L.J. Zhang, J.L. Zhao, H.C. Su, B. Yang, S. Liu, Use of TIE techniques to characterize industrial effluents in the Pearl River Delta region, Ecotoxicol. Environ. Saf. 76 (2012) 143-152.

21] F. Wang, A.O.W. Leung, S.C. Wu, M.S. Yang, M.H. Wong, Chemical and ecotoxicological analyses of sediments and elutriates of contaminated rivers due to e-waste recycling activities using a diverse battery of bioassays, Environ. Pollut. 157 (2009) 2082-2090.

22] K.W Gaido, L.S. Leonard, S. Lovell, J.C Gould, R.D. Babai, CJ Portier, D.P. McDonnell, Evaluation of chemicals with endocrine modulating activity in a yeast-based steroid hormone receptor gene transcription assay, Toxicol. Appl. Pharmacol. 143 (1997) 205-212.

[23] H.A. Balsiger, R. de la Torre, W.Y. Lee, M.B. Cox, A four-hour yeast bioassay for the direct measure of estrogenic activity in wastewater without sample extraction, concentration, or sterilization, Sci, Total Environ. 408 (2010) 1422-1429.

[24] A.C. Gutleb, I.A.T.M. Meerts, J.H. Bergsma, M. Schriks, A.J. Murk, T-screen as tool to identify thyroid hormone receptor active compounds, Environ. Toxicol. Pharmacol. 19 (2005) 231-238.

[25] R.H. Dai, H.J. Liu, J.H. Qu, J. Ru, Y.Hou, Cyanobacteria and their toxins in Guanting Reservoir of Beijing, China, J. Hazard. Mater. 153 (2008) 470-477.

[26] J.W. Chen, C. Liu, Z.F. Yang, J.Y. Wang, Residues and characteristics of organochlorine pesticides in the surface water in the suburb of Beijing, Earth. Sci. Front. 15 (2008) 242-247.
[27] Y.W. Wan, T.F. Kang, Z.L. Zhou, Y.Zhang, Distribution and health risk assessment of organochlorine pesticides in Beijing Guanting Reservoir, J. Agro-Environ. Sci. 28 (2009) 803-807.

[28] H.LA Sonneveldt, R.W.P.M. Laane, Prediction of sediment quality in the Dutch coastal zone: model validation and uncertainty analysis for $\mathrm{Cd}, \mathrm{Cu}, \mathrm{Pb}, \mathrm{Zn}, \mathrm{PCBs}$ and PAHs, in: P.S. Rainbow, S. Hopkin, M. Crane (Eds.), Forecasting the Environmental Fate and Effects of Chemical, John Wiley and Sons Ltd., Chichester, 2001, pp. 177-189.

[29] G.T. Ankley, K. Lodge, D.J. Call, M.D. Balcer, L.T. Brooke, P.M. Cook, R.G. Kreis A.R. Carlson, R.D. Johnson, G.J. Niemi, R.A. Hoke, C.W. West, J.P. Giesy, P.D. Jones, Z.C. Fuying, Integrated assessment of contaminated sediments in the Lower Fox and Green Bay, Wisconsin, Ecotoxicol. Environ. Saf. 23 (1992) 46-63.

[30] USEPA/USACE, Evaluation of Dredged Material Proposed for Ocean Disposa (Testing Manual), USEPA Office of Marine and Estuaries Protection, and Department of the Army, USACE, Washington, DC, 1991.

[31] Y.H. Cheung, A. Neller, K.H. Chu, N.F.Y. Tam, C.K. Wong, Y.S. Wong, M.H. Wong Assessment of sediment toxicity using different trophic organisms, Arch. Environ. Contam. Toxicol. 32 (1997) 260-267.

[32] W. Shi, X.Y. Wang, G.J. Hu, Y.Q. Hao, X.W. Zhang, H.L. Liu, S. Wei, X.R. Wang, H.X. Yu, Bioanalytical and instrumental analysis of thyroid hormone disrupting compounds in water sources along the Yangtze River, Environ. Pollut. 159 (2011) 441-448.

[33] J. Li, Z.J. Wang, M. Ma, X. Peng, Analysis of environmental endocrine disrupting activities using recombinant yeast assay in wastewater treatment plant effluents, Bull. Environ. Contam. Toxicol. 84 (2010) 529-535.

[34] N. Li, M. Ma, K.F. Rao, Z.J. Wang, In vitro thyroid disrupting effects of organic extracts from WWTPs in Beijing, J. Environ. Sci. (China) 23 (2011) 671-675.

[35] L. Wada, J.C. King, Effect of low zinc intakes on basal metabolic rate, thyroid hormones and protein utilization in adult men, J. Nutr. 116 (1986) 1045-1053.

[36] M.I. Surks, I.J. Ramirez, L.E. Shapiro, M. Kumara-Siri., Effect of zinc (II) and other divalent cations on binding of 3,5,3'-triiodo-L-thyronine to nuclear receptors from cultured GC cells, J. Biol. Chem. 264 (1989) 9820-9826.

[37] M.P. Sciaudone, S. Chattopadhyay, H.C. Freake, Chelation of zinc amplifies induction of growth hormone mRNA levels in cultured rat pituitary tumor cells, J. Nutr. 130 (2000) 158-163.

[38] USEPA, The Incidence and Severity of Sediment Contamination in Surface Waters of the United States, National Sediment Quality Survey, second ed. USEPA, Washington, DC, 2004. 